\title{
Seismic Response of Base Isolated Liquid Storage Tanks under Near Fault Ground Motions
}

\author{
By Saman Bagheri* \\ Mostafa Farajian ${ }^{\dagger}$
}

\begin{abstract}
Among the different base isolation systems, the Friction Pendulum System (FPS), whose period does not depend on the weight of the structure, are more appropriate for the isolation of liquid storage tanks. In this paper, the seismic behavior of the cylindrical liquid storage tanks base isolated by FPS is investigated under near-fault ground motions. Such earthquake ground motions have long-period components that may affect the long-period sloshing motion of the liquid. For the required analyses, the isolated tank-liquid system is modeled as three lumped masses known as convective mass, impulsive mass and base mass. The interaction between the fluid and the structure has been taken into account by connecting the liquid masses to the tank wall with specific springs and dampers. Nonlinear time history analyses are carried out to investigate the effects of the isolation period. The results obtained indicate that the friction pendulum system reduces the response parameters of the base isolated tank in comparison with the fixed-base tank.
\end{abstract}

Keywords: Base isolation, FPS, Near-fault ground motions, Liquid storage tank

\section{Introduction}

Because of the interaction of fluid and structure, cylindrical liquid storage tanks behave differently from other structures such as buildings and bridges. The flaming, buckling of the wall, uplifting of the tank, and roof's damage demonstrate the inappropriate performance of the storage tanks in the previous earthquakes (Cooper, 1997; Hamdan, 2000). There are several methods to reduce the damages in these structures. One of these methods is to use passive control devices such as dampers and base isolators. Chalhoub and Kelly (1990) conducted shake table tests of fixed base and base isolated cylindrical water tanks. The results showed that due to the reduction in the input accelerations, the dynamic pressure was reduced considerably for the tank in the isolated structure, while the convective displacement of the fluid was slightly increased. Zayas and Low (1995) used a friction pendulum system in a LNG tank and mentioned several benefits of it in industrial tanks. Malhotra (1997a; 1997b) proposed a method for seismic base isolation of on-grade cylindrical liquid

* Assistant Professor, University of Tabriz, Iran.

+ Graduate Student, University of Tabriz, Iran. 
storage tanks in which the base plate was supported directly on the ground, and the tank wall was supported on a ring of flexible bearings. Obtained numerical results demonstrated that the isolation reduced the overturning moments and the axial compressive stresses in the tank.

The response of the liquid storage tanks isolated by the sliding bearings subjected to bi-directional earthquake ground motions was investigated by (Shrimali and Jangid, 2002a). They also performed a comparative study of the performance of various isolation systems for liquid storage tanks such as the laminated rubber bearing, lead-rubber bearing, pure-friction system, friction pendulum system, resilient-friction base isolator, and the electric de France system (Shrimali and Jangid, 2002b). The results showed that the sliding type isolation systems were more effective in controlling the seismic response of the tanks in comparison with the elastomeric bearings. A review of the seismic behavior of the isolated liquid storage tanks has been recently presented by (Panchal and Soni, 2014).

Among the various sliding type seismic isolation systems, the Friction Pendulum System (FPS) is one of the most effective and frequently used ones. Whereas the volume of the filling fluid in a storage tank and therefore the weight of the structure are not exactly specified at the time of the earthquake, it seems that the FPS has a better performance because the period of the isolation system does not depend on the mass of the superstructure. Paolacci analyzed and compared the performance of the high damping rubber bearings (HDRB) and friction pendulum isolators (FPS) for the seismic isolation of the elevated liquid storage tanks (Paolacci, 2015). The numerical results proved the high effectiveness of both isolation systems in reducing the seismic responses; however the adoption of FPS rather than HDRB in the seismic isolation of elevated tanks was suggested because of the lower value of vertical sloshing displacements. Moreover, the seismic behavior of the elevated liquid storage tanks isolated by multi-phase friction pendulum systems was investigated (Moeindarbari et al., 2014). The effect of the soil-structure interaction on the seismic behavior of the FPS-isolated structures was also investigated by (Krishnamoorthy and Anita, 2016) using a finite element method.

The seismic response of the liquid storage tanks, especially subjected to near-fault ground motions, has unique characteristics. Such earthquake records have long-period components that may affect the long-period sloshing motion of the liquid (Bagheri et al., 2005). In this paper, seismic performance of cylindrical liquid storage tanks isolated by FPS under near fault ground motions is investigated. For this purpose, nonlinear time history analyses are done to compare the responses of both broad and slender base isolated storage tanks with fixed ones. Then the effect of the base isolation's period on the seismic response parameters is calculated. 


\section{Simplified Fluid-Structure Interaction}

The 3-D Finite element model of a base isolated liquid storage tank is complicated due to fluid-structure interaction of the system. Housner (1963) proposed a simple approximate method to estimate the dynamic effects of liquid in a rigid fixed base tank under the horizontal seismic excitation. Later on, Haroun and Housner (1981) modified Housners' model to take into account the flexibility of the tank wall. They introduced a mechanical model to estimate the seismic response of cylindrical liquid storage tanks in the form of generalized single-degree-of freedom system representing the impulsive and convective modes of vibration of the tank-liquid system. In such a model, the impulsive component represents the action of the liquid that moves in unison with the tank wall, while the convective component represents the action of the liquid that experiences sloshing motion near the free-surface.

Malhotra et al. (2000) combined the higher impulsive modal mass with the first impulsive mode and the higher convective modal mass with the first convective mode to represent the tank-liquid system with two modes only. The mathematical model used in the present study is based on this simple, yet accurate, and more generally applicable model. This is shown in Figure 1. The geometrical parameters of the tank are the liquid height $(H)$, radius of the tank $(R)$, and the equivalent uniform thickness of the tank wall $(t)$. The convective and impulsive masses $\left(m_{c}\right.$ and $\left.m_{i}\right)$ are connected to the tank wall by springs having stiffnesses of $k_{c}$ and $k_{i}$, respectively. The damping coefficients of the convective and impulsive masses are denoted as $c_{c}$ and $c_{i}$, respectively.

Figure 1. A Typical Base Isolated Liquid Storage Tank; (a) A Detailed View, (b) Simplified Mass-Spring Model

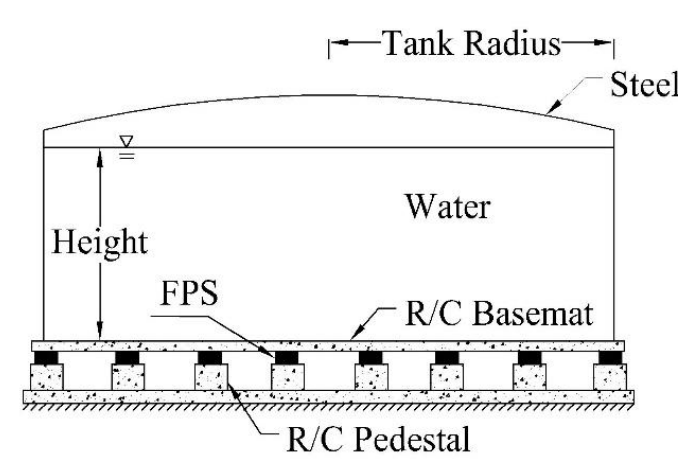

(a)

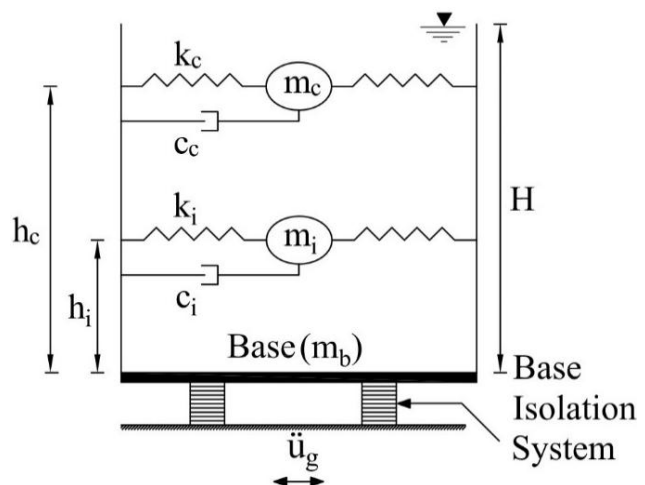

(b)

The natural periods of the convective $\left(T_{c}\right)$ and impulsive $\left(T_{i}\right)$ responses are (Malhotra et al., 2000):

$$
\begin{aligned}
& T_{c}=C_{c} \sqrt{R} \\
& T_{i}=C_{i} \frac{H \sqrt{\rho}}{\sqrt{t / R} \times \sqrt{E}}
\end{aligned}
$$


where $\rho$ is the mass density of liquid, and $E$ is the modulus of the elasticity of the tank material. The coefficients $C_{c}$ and $C_{i}$, as well as the relative convective and impulsive masses $\left(m_{d} / m\right.$ and $\left.m_{i} / m\right)$ and heights $\left(h_{d} / H\right.$ and $\left.h_{i} / H\right)$ can be obtained from (Malhotra et al., 2000) as functions of $H / R$. The total liquid mass $(m)$ is obviously equal to $\pi R^{2} H \rho$. Consequently, the equivalent stiffness and damping coefficients of the convective and impulsive masses are given by:

$$
\begin{aligned}
& k_{c}=m_{c} \times \frac{4 \pi^{2}}{T_{c}^{2}} \\
& k_{i}=m_{i} \times \frac{4 \pi^{2}}{T_{i}^{2}} \\
& c_{c}=2 \xi_{c} m_{c} \times \frac{2 \pi}{T_{c}} \\
& c_{i}=2 \xi_{i} m_{i} \times \frac{2 \pi}{T_{i}}
\end{aligned}
$$

where, $\xi_{c}$ and $\xi_{i}$ are the damping ratios of the convective and impulsive modes, respectively.

\section{Governing Equations of Motion}

Figure 2 shows the three-degree of the freedom system of a base isolated liquid storage tank. The equations of motion can be expressed as follows:

$$
\begin{aligned}
& m_{c} \ddot{u}_{c}+c_{c}\left(\dot{u}_{c}-\dot{u}_{b}\right)+k_{c}\left(u_{c}-u_{b}\right)=-m_{c} \ddot{u}_{g} \\
& m_{i} \ddot{u}_{i}+c_{i}\left(\dot{u}_{i}-\dot{u}_{b}\right)+k_{i}\left(u_{i}-u_{b}\right)=-m_{i} \ddot{u}_{g} \\
& m_{b} \ddot{u}_{b}-k_{c}\left(u_{c}-u_{b}\right)-k_{i}\left(u_{i}-u_{b}\right)-c_{c}\left(\dot{u}_{c}-\dot{u}_{b}\right)-c_{i}\left(\dot{u}_{i}-\dot{u}_{b}\right)+c_{b} \dot{u}_{b}+F=-m_{b} \ddot{u}_{g}
\end{aligned}
$$

where $u_{c}, u_{i}$, and $u_{b}$ are displacements relative to the ground for the convective, impulsive, and base masses respectively; $\ddot{u}_{\mathrm{g}}$ is the earthquake ground acceleration; $F$ is the horizontal force exerted by FPS; $m_{b}$ is the base mass, and $c_{b}$ is the additional viscous damping at the base level which is defined as:

$c_{b}=2 M \xi_{b} \omega_{b}=2 M \xi_{b} \times \frac{2 \pi}{T_{b}}$

where $\xi_{b}$ is the damping ratio of the additional viscous damper at the base level; $T_{b}$ is the isolation period, and $M$ is the total mass of the superstructure plus that of the base slab (Kelly, 1997), i.e. $m_{c}+m_{i}+m_{b}$. The isolation period, $T_{b}$, and the horizontal force exerted by FPS, $F$ are given as:

$$
\begin{aligned}
& T_{b}=2 \pi \sqrt{\frac{R}{g}} \\
& F=\frac{W}{R} u_{b}+\mu W \operatorname{sgn}\left(\dot{u}_{b}\right)
\end{aligned}
$$

where $W$ is the vertical load on the isolator produced by the weight of the system (equal to $M g$ ), $R$ is the radius of curvature of the sliding surface, and $\mu$ is the velocity dependent coefficient of the friction. In the aforementioned force of Eq. (12), the first term is the linear elastic spring force with its stiffness 
based on the curvature of the spherical dish and the second term is the friction force.

Figure 2. Three-degree of Freedom System of Considered Base Isolated Tank

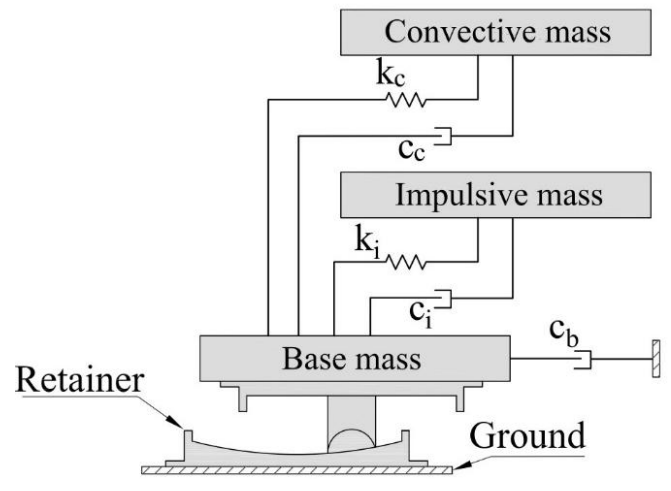

Using the state-space representation, a MATLAB routine is provided to solve the governing equations of motion. In the state-space formulation, the three second-order differential equations, i.e., Eqs. (7) to (9) are converted to six equivalent first-order differential equations. Then, Runge-Kutta 4th order method is used to numerically solve these nonlinear equations with the MATLAB ode45 solver. The numerical results will be mainly presented in terms of the convective and impulsive displacements relative to the base $\left(x_{c}, x_{i}\right)$ according to Eqs. (13), (14), and structural base shear $\left(F_{s}\right)$ according to Eq. (15).

$x_{c}=u_{c}-u_{b}$

$x_{i}=u_{i}-u_{b}$

$F_{s}=-\left\{m_{c}\left(\ddot{u}_{c}+\ddot{u}_{g}\right)+m_{i}\left(\ddot{u}_{i}+\ddot{u}_{g}\right)\right\}$

\section{Numerical Study}

A parametric study has been done to compute the efficiency of FPS. For this purpose, a broad and a slender base isolated steel tank have been considered for the numerical study. The resulted seismic responses of the isolated tanks are compared with those of the fixed ones. The geometric properties of the tank models are summarized in Table 1 and the resultant parameters of the equivalent mechanical models are listed in Table 2 . The damping ratios for convective and impulsive masses are taken as $0.5 \%$ and $2 \%$, respectively, as suggested previously for steel liquid storage tanks (Malhotra, 1997b; Haroun and Housner, 1981; Malhotra et al. 2000).

Table 1. Properties of the Broad and Slender Tanks Used in this Study

\begin{tabular}{lllllll}
\hline Tank type & $H(\mathrm{~m})$ & $R(\mathrm{~m})$ & $H / R$ & $t(\mathrm{~m})$ & $E(\mathrm{GPa})$ & $\rho\left(\mathrm{kg} / \mathrm{m}^{3}\right)$ \\
\hline Broad & 14.6 & 24.4 & 0.6 & 0.0203 & 200 & 1000 \\
Slender & 11.3 & 6.1 & 1.85 & 0.0058 & 200 & 1000 \\
\hline
\end{tabular}


Table 2. Resultant Parameters of the Equivalent Mechanical Model for the Broad and Slender Tanks

\begin{tabular}{lllllllll}
\hline Tank type & $m_{c} / m$ & $m_{i} / m$ & $h_{c} / H$ & $h_{i} / H$ & $C_{c}\left(\mathrm{~s} / \mathrm{m}^{0.5}\right)$ & $C_{i}$ & $T_{c}(\mathrm{~s})$ & $T_{i}(\mathrm{~s})$ \\
\hline Broad & 0.608 & 0.392 & 0.557 & 0.400 & 1.65 & 7.08 & 8.15 & 0.253 \\
Slender & 0.245 & 0.755 & 0.727 & 0.444 & 1.48 & 6.07 & 3.66 & 0.157 \\
\hline
\end{tabular}

Table 3. Selected Near-fault Earthquake Records for Time History Analyses

\begin{tabular}{llll}
\hline No. & Earthquake & Station & PGA (g) \\
\hline 1 & Northridge 1994 & 77 Rinaldi Receiving Sta & 0.825 \\
2 & Northridge 1994 & 24514 Sylmar & 0.843 \\
3 & Loma Prieta 1989 & LGP & 0.570 \\
4 & ChiChi 1999 & TCU068-E & 0.512 \\
5 & ChiChi 1999 & TCU075-W & 0.333 \\
6 & Imperial Valley 1979 & 5165 El-Centro Diff. Array & 0.352 \\
\hline
\end{tabular}

The characteristics of the selected near-fault ground motion records for time history analyses are shown in Table 3. These selected ground motions have been recorded close to faults and have revealed near-fault pulses.

\section{Results and Discussion}

\section{Effect of Base Isolation}

The time history of various response parameters of broad and slender tanks under the Imperial Valley 1979- El-Centro ground motion is shown in Figure 3. The responses are shown for both isolated and fixed base conditions. The isolation parameters of FPS are: isolation period, $T_{b}$, maximum and minimum coefficients of sliding friction, $\mu_{\max }$ and $\mu_{\min }$. The values considered for the present study are $T_{b}=2 \mathrm{sec}$., $\mu_{\max }=0.06$ and $\mu_{\min }=0.03$.

It is observed that there is a significant reduction in base shear and impulsive displacement for both broad and slender tanks indicating that FPS is quite effective in reducing the seismic response of cylindrical liquid storage tanks. Such reductions will lead to better performance of these structures during earthquake events.

The peak response parameters of broad and slender cylindrical liquid storage tanks under different earthquakes are shown in Table 4. It is observed that due to isolation, maximum base shear and impulsive displacement are significantly reduced in all six considered earthquakes. The average percentage reductions in the base shear are 66\% and 66\%; and in the impulsive displacement are $66 \%$ and $65 \%$ for broad and slender tanks, respectively. The table also shows that, as a result of isolation, there is a moderate increase in the convective displacement in some earthquakes. 
Figure 3. Time History of Various Response Parameters of Broad and Slender Tanks under Imperial Valley Earthquake
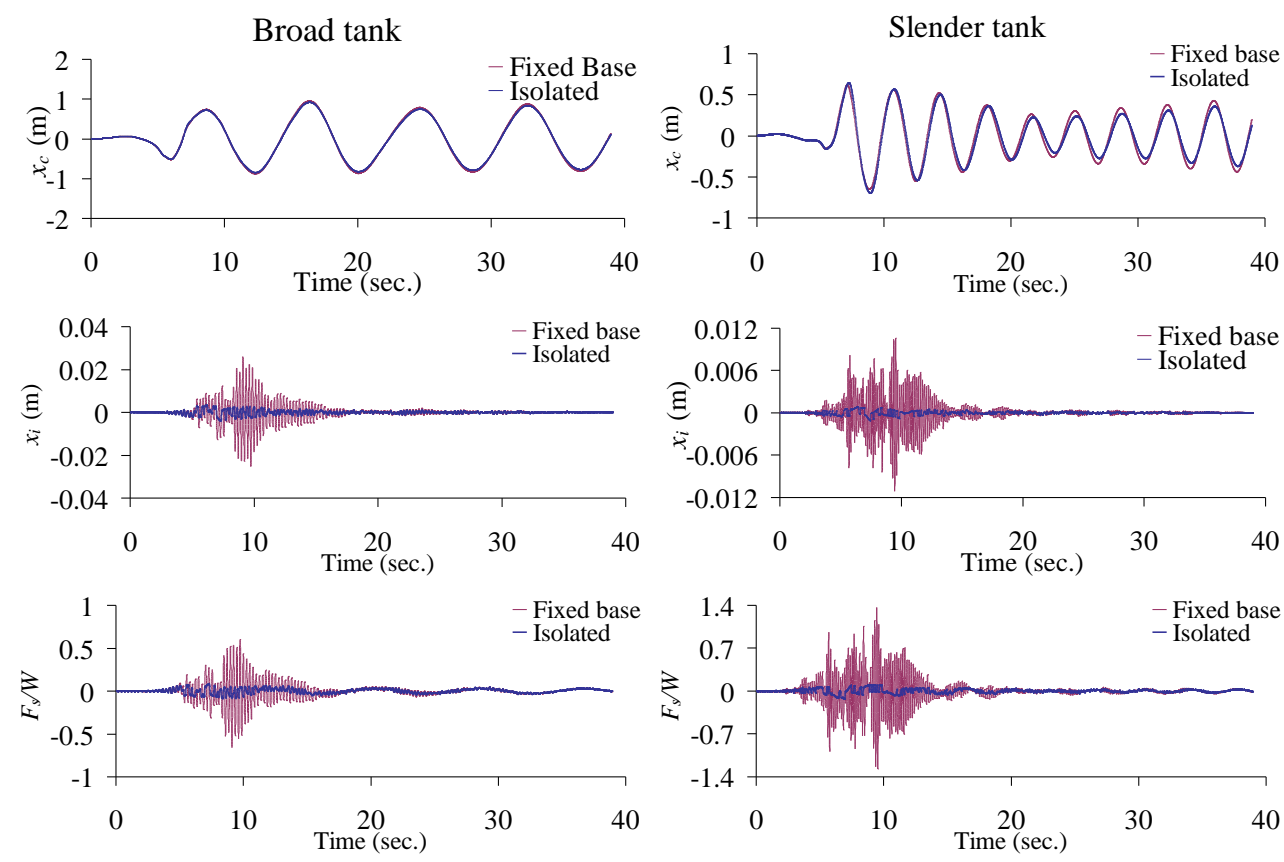

Table 4. Peak Response Parameters of Broad and Slender Tanks

\begin{tabular}{|c|c|c|c|c|c|c|c|c|}
\hline \multirow{2}{*}{\multicolumn{2}{|c|}{ No. Earthquake }} & \multirow{2}{*}{ Type of Tank } & \multicolumn{3}{|c|}{ Broad Tank } & \multicolumn{3}{|c|}{ Slender Tank } \\
\hline & & & $x_{c}(\mathrm{~m})$ & $x_{i}(\mathrm{~m})$ & $F_{s} / W$ & $x_{c}(\mathrm{~m})$ & $x_{i}(\mathrm{~m})$ & $F_{s} / W$ \\
\hline \multirow{2}{*}{1} & \multirow{2}{*}{$\begin{array}{l}\text { Northridge- } \\
\text { Rinaldi }\end{array}$} & Fixed-base & 0.378 & 0.0406 & 0.994 & 0.682 & 0.00813 & 1.015 \\
\hline & & Isolated & 0.604 & 0.0185 & 0.445 & 0.766 & 0.00426 & 0.465 \\
\hline \multirow{2}{*}{2} & \multirow{2}{*}{$\begin{array}{l}\text { Northridge- } \\
\text { Sylmar }\end{array}$} & Fixed-base & 0.471 & 0.0281 & 0.680 & 0.706 & 0.00855 & 1.099 \\
\hline & & Isolated & 0.604 & 0.0101 & 0.224 & 1.096 & 0.00355 & 0.395 \\
\hline \multirow[t]{2}{*}{ 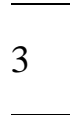 } & \multirow{2}{*}{ Loma Prieta } & Fixed-base & 0.544 & 0.0280 & 0.695 & 1.425 & 0.01459 & 1.860 \\
\hline & & Isolated & 0.589 & 0.0087 & 0.199 & 1.723 & 0.00292 & 0.370 \\
\hline \multirow{2}{*}{4} & \multirow{2}{*}{$\begin{array}{l}\text { ChiChi- } \\
\text { TCU068 }\end{array}$} & Fixed-base & 5.419 & 0.0202 & 0.536 & 1.673 & 0.00500 & 0.601 \\
\hline & & Isolated & 5.332 & 0.0103 & 0.309 & 2.077 & 0.00295 & 0.406 \\
\hline \multirow{2}{*}{5} & \multirow{2}{*}{$\begin{array}{l}\text { ChiChi- } \\
\text { TCU075 }\end{array}$} & Fixed-base & 1.496 & 0.0196 & 0.465 & 1.681 & 0.00582 & 0.793 \\
\hline & & Isolated & 1.445 & 0.0045 & 0.120 & 1.311 & 0.00161 & 0.226 \\
\hline \multirow{2}{*}{6} & \multirow{2}{*}{$\begin{array}{l}\text { Imperial } \\
\text { Valley }\end{array}$} & Fixed-base & 0.952 & 0.0262 & 0.670 & 0.651 & 0.01100 & 1.376 \\
\hline & & Isolated & 0.919 & 0.0040 & 0.088 & 0.697 & 0.00109 & 0.128 \\
\hline
\end{tabular}

\section{Effect of Isolation Period}

The effect of the isolation period on the seismic responses of the broad and slender tanks under different earthquakes is shown in Figure 4. It is observed that the peak base shear and impulsive displacement decrease, as the isolation period increases. This is due to the fact that with an increase in isolation period the FPS becomes more flexible and as a result, transmits less earthquake acceleration into the tank, leading to a reduction in the base shear. 
Furthermore, the convective displacement of the tank is earthquake dependent and is generally less sensitive to the isolation period.

Figure 4. Effect of Isolation Period on Peak Responses of Isolated Tanks

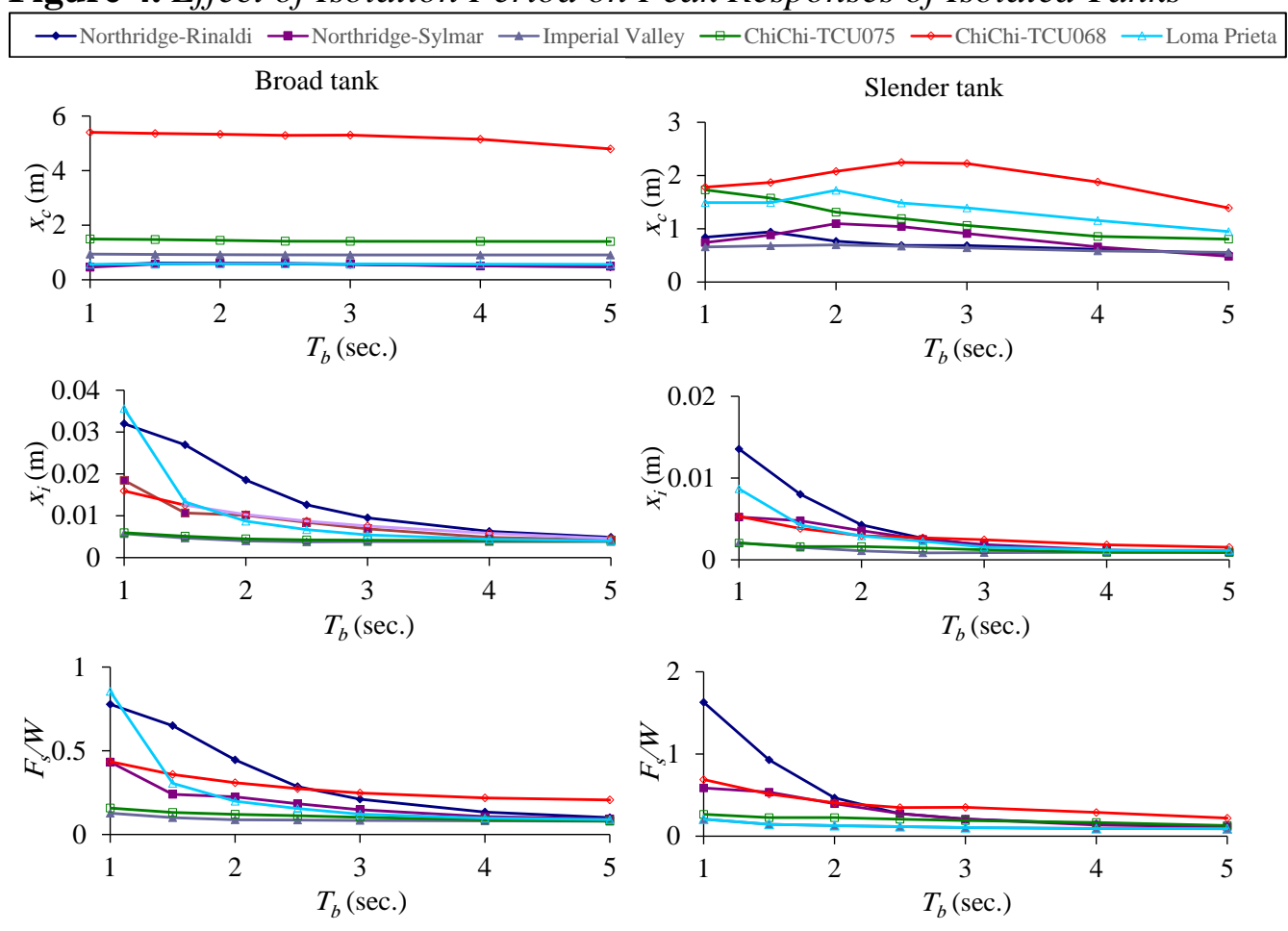

\section{Conclusions}

In this paper, the effectiveness of FPS in reducing the seismic responses of cylindrical liquid storage tanks was investigated under near-fault strong ground motions. It was found that the Friction Pendulum System is a quite effective isolation system in order to reduce the tank responses such as base shear and impulsive displacement. However, under some earthquakes, there is a moderate increase in the convective displacement when the tank is seismically isolated. In addition, it is found that the peak base shear and impulsive displacement decreases, as the isolation period increases. However, for the isolation periods of more than about $4 \mathrm{sec}$., isolation period has no significant effect on the peak responses.

\section{References}

Bagheri, S., Rofooei, F. and Bozorgnia, Y. (2005). Evaluation of the seismic response of liquid storage tanks, Proceedings of the Tenth International Conference on Civil, Structural and Environmental Engineering Computing, Rome, Italy.

Chalhoub, M. S. and Kelly, J. M. (1990). Shake table test of cylindrical water tanks in base-isolated structures, Journal of Engineering Mechanics, 116(7): 1451-1472. 
Cooper, T. W. (1997). A study of the performance of petroleum storage tanks during earthquakes, 1933-1995, Report for US Department of Commerce: NIST GCR 97720.

Hamdan, F. H. (2000). Seismic behaviour of cylindrical steel liquid storage tanks, Journal of Constructional steel Research, 53(3): 307-333.

Haroun, M. A. and Housner, G. W. (1981). Seismic design of liquid storage tanks, Journal of the Technical Councils of ASCE, 107(1): 191-207.

Housner, G. W. (1963). The dynamic behavior of water tanks, Bulletin of the Seismological Society of America, 53(2): 381-387.

Kelly, J. M. (1997). Earthquake resistant design with rubber, Second edition, Springer, London.

Krishnamoorthy, A. and Anita, S. (2016). Soil-structure interaction analysis of a FPSisolated structure using finite element model, Structures, 5: 44-57.

Malhotra, P. K. (1997a). Method for seismic base isolation of liquid storage tanks, Journal of Structural Engineering, 123(1): 113-116.

Malhotra, P. K. (1997b). New method for seismic isolation of liquid storage tanks, Earthquake Engineering and Structural Dynamics, 26(8): 839-847.

Malhotra, P. K., Wenk, T. and Wieland, M. (2000). Simple procedure for seismic analysis of liquid-storage tanks, Structural Engineering International, 10 (3): 197-201.

Moeindarbari, H., Malekzadeh, M. and Taghikhany, T. (2014). Probabilistic analysis of seismically isolated elevated liquid storage tank using multi-phase friction bearing, Earthquakes and Structures, 6(1): 111-125.

Panchal, V. R. and Soni, D. P. (2014). Seismic behaviour of isolated fluid storage tanks: A-state-of-the-art review, KSCE Journal of Civil Engineering, 18(4), 10971104.

Paolacci, F. (2015). On the effectiveness of two isolation systems for the seismic protection of elevated tanks, Journal of Pressure Vessel Technology, 137(3), 031801/1-8.

Shrimali, M. K. and Jangid, R. S. (2002a). Seismic response of liquid storage tanks isolated by sliding bearings, Engineering Structures, 24(7): 909-921.

Shrimali, M. K. and Jangid, R. S. (2002b). A comparative study of performance of various isolation systems for liquid storage tanks, International Journal of Structural Stability and Dynamics, 2(4): 573-591.

Zayas, V. A. and Low, S. S. (1995). Application of seismic isolation to industrial tanks, ASME/JSME Proceedings of Pressure Vessels and Piping Conference, Hawaii, USA, 319: 273-286. 
